Article

\title{
Assessment of Layer-By-Layer Modified Nanofiltration Membrane Stability in Phosphoric Acid
}

\author{
Kirsten Remmen ${ }^{1}$, Barbara Müller ${ }^{1}$, Joachim Köser ${ }^{2}$, Matthias Wessling ${ }^{3}$ \\ and Thomas Wintgens ${ }^{1,4, *}$
}

1 School of Life Sciences, Institute for Ecopreneurship, University of Applied Sciences and Arts Northwestern Switzerland, Hofackerstrasse 36, 4132 Muttenz, Switzerland; kirsten.remmen@fhnw.ch (K.R.);

barbara.mueller@hotmail.com (B.M.)

2 School of Life Sciences, Institute for Bioanalytics, University of Applied Sciences and Arts Northwestern Switzerland, Hofackerstrasse 36, 4132 Muttenz, Switzerland; joachim.koeser@fhnw.ch

3 Chemical Process Engineering, RWTH Aachen University, Forckenbeckstrasse 51, 52074 Aachen, Germany; matthias.wessling@avt.rwth-aachen.de

4 Institute of Environmental Engineering (ISA), RWTH Aachen University, Mies-van-der-Rohe-Str. 1, 52074 Aachen, Germany

* Correspondence: wintgens@isa.rwth-aachen.de

Received: 28 February 2020; Accepted: 31 March 2020; Published: 3 April 2020

check for updates

\begin{abstract}
Nanofiltration (NF) can enable P recovery from waste streams via retaining multivalent impurities from spent pickling acid. However, with the currently available membranes, an economically feasible process is impossible. Layer-by-layer modified NF membranes are a promising solution for the recovery of $\mathrm{P}$ from acidic leachate. LbL membranes show a high level of versatility in terms of fine tuning for ion retention, which is necessary to achieve sufficient phosphorus yields. However, the stability of layer-by-layer modified membranes during phosphoric acid $\left(\mathrm{H}_{3} \mathrm{PO}_{4}\right)$ filtration needs to be further investigated. In our study, we show that a polyethersulfone hollow fiber membrane modified with four or eight bi-layers was stable during immersing and filtering of a $15 \% \mathrm{H}_{3} \mathrm{PO}_{4}$ solution. A sulfonated polyethersulfone (sPES)-based hollow fiber LbL membrane was only stable during filtration. Thus, we show the importance of applying real process conditions to evaluate membranes. Another important aspect is the influence of the high ionic strength of the feed solution on the membrane. We show that a high ionic strength led to a decrease in Mg retention, which could be increased to $85 \%$ by adjusting the process parameters.
\end{abstract}

Keywords: LbL modified membranes; acid stable membrane; phosphorus recovery

\section{Introduction}

Acids such as sulphuric acid, hydrochloride acid, and phosphoric acid are used in pickling bathes to treat metal surfaces. During this process, the acid is enriched with metal elements, therefore after a certain time the acid is spent and needs to be renewed. Even though there are possible technologies allowing acid recycling, the most common disposal route for spent mixed pickling acid is still neutralization of the acid using lime. The dissolved metals are precipitated as their salts. Hence, no resource recovery, neither of the metals nor of the acid, takes place [1].

This is mainly due to several drawbacks of the available technologies (e.g., in terms of energy consumption, high emission levels, low recycling, high fresh water supply) [1-3]. It also needs to be pointed out that various pickling acids have varying recycling potential. Electro dialysis and diffusion dialysis show good results for the purification and recycling of $\mathrm{HNO}_{3} / \mathrm{HF}, \mathrm{HCl}$ and $\mathrm{H}_{2} \mathrm{SO}_{4}$ 
mixtures [1,2]. However, these technologies are not very suitable for spent $\mathrm{H}_{3} \mathrm{PO}_{4}$ recovery. The high energy consumption, which occurs when separating concentrated $\mathrm{H}_{3} \mathrm{PO}_{4}$, leads to an economically and ecologically unfavorable process [4]. Nonetheless, P recycling is essential as it is considered a critical raw material by the European Union [5]. In addition, the production of phosphoric acid has a huge environmental impact. Each tonne of phosphoric acid produced makes fivefold the amount of hazardous waste [6,7]. During production, raw $\mathrm{H}_{3} \mathrm{PO}_{4}$ must be purified of impurities such as Fe, $\mathrm{Mg}$, $\mathrm{Al}, \mathrm{V}, \mathrm{Zn}, \mathrm{Cd}$, and $\mathrm{Ca}$. This is mainly carried out using solvent extraction, involving an extensive preand post-treatment. Solvent extraction processes have significant environmental impacts due to their resource intensity [1-3]. Hence, currently no satisfactory "green" recovery technology for $\mathrm{H}_{3} \mathrm{PO}_{4}$ from spent pickling acid is available.

Nanofiltration (NF) is a well-established process for all kinds of industrial separations, but spent pickling $\mathrm{H}_{3} \mathrm{PO}_{4}$ recovery is not one of them yet [3]. The application of NF for spent pickling acid and pickling baths, especially $\mathrm{H}_{3} \mathrm{PO}_{4}$, is still an emerging technology [3,8]. The applicability of NF was shown for P recovery from sewage sludge [9-11]. P concentrations in the acidified sewage sludge ash are much lower than in pickling acids. Nevertheless, the transport mechanisms of $\mathrm{P}$ through the membrane is the same. In the studies by Schütte et al. or Niewersch, commercially available membranes were used to retain metals and heavy metals but allow the permeation of $\mathrm{P}$ in the form of $\mathrm{H}_{3} \mathrm{PO}_{4}$. The concept was proven to be successful, yet the process is not economically feasible due to high $\mathrm{P}$ retention and low fluxes [9-11]. Schütte et al. concluded that for the recovery of metal contaminated $\mathrm{H}_{3} \mathrm{PO}_{4}$ solutions, a highly permeable membrane with a low retention for $\mathrm{H}_{3} \mathrm{PO}_{4}$ and highly positively charged ion retention is favourable.

Currently, such a membrane is commercially not available. This problem can be overcome by modifying membranes using polyelectrolyte (PE) layer-by-layer (LbL) deposition, creating NF membranes with tailor-made characteristics [12-22]. LbL membranes are fabricated by depositing oppositely charged PE on an also charged support material, in general a porous ultrafiltration (UF) membrane.

Due to the high fluxes, this novel technique was successfully applied, overcoming the above mentioned drawbacks (low flux, low P-yield) of commercially available membranes [12,23]. In addition, LbL assembly gives the membrane tailored properties such as charge, hydrophilicity, chemical resistance, high flux, resistance to fouling and therefore an overall improvement of the separation process.

However, little is known for such membranes with respect to acid resistance, acid permeability and impurity rejection. In the two previous studies carried out by us we successfully showed that LbL membranes outperform commercial membranes in terms of permeability and P recovery from an acidic environment [12,23]. It was shown that over $80 \%$ permeate recovery can be reached by filtrating with $10 \%$ phosphoric acid, while constantly achieving less than $20 \%$ P retention. Hence, it was possible to reach at least $75 \%$ P recovery. This recovery rate was achieved using a PES(PDAMAC/PSS) 6 membrane [12]. However, these studies do not describe the impact of phosphoric acid on the stability of the membrane.

Besides our studies, very few publications have reported on the behavior of PE in an acidic environment. In most of these studies either weak PE were chosen, which were not stable at low $\mathrm{pH}$ levels, or the $\mathrm{pH}$ was not decreased below 3.5, as is needed to truly estimate the behavior of LbL membranes during harsh acidic applications [24-26], whereas strong PE such as PDAMAC and PSS are constantly charged independent of $\mathrm{pH}$. Menne et al. [13] also showed excellent $\mathrm{pH}$ stability $(0-14)$ of PE coated on ceramic UF membranes in $\mathrm{HCl}$. In the described study, a ceramic membrane coated with three bi-layers was exposed up to a $1 \mathrm{M} \mathrm{HCl}$ solution for several hours and was shown to remain stable [13]. We also reported good stability for polymeric LbL membranes in a $1 \mathrm{M} \mathrm{HCl}$ solution [27]. In a study by Nehme et al. [28], coated capillaries were rinsed with $1 \mathrm{M} \mathrm{HCl}$ for $30 \mathrm{~min}$. The coating of the capillaries was not affected by this acidic treatment [28]. These studies showed that the polyelectrolyte membranes (PEM) were stable in a harsh acidic environment [28-30]. 
These promising approaches were picked up on in this study and further developed to investigate its application to $\mathrm{H}_{3} \mathrm{PO}_{4}$ recovery in industrial processes. One parameter investigated in our study was the retention values for a highly osmotic solution. This is especially interesting in terms of later applications in acidic solutions, which often contain large amounts of salts and metals. Previous studies have shown that even though PDADMAC/PSS multilayer coatings are stable for a month if preserved in deionized water, they are highly sensitive to ionic strength, shear forces, and temperature changes [31-33]. Gao et al. pointed out that high ionic strength leads to variations in PDADMAC/PSS structure; however, in their case, the terminating layer was PDADMAC, which is known to be more sensitive to swelling than other PEs [31]. A change in the structure of the layers does not necessarily lead to a poor performance of the membrane. Hence, it is important to observe the properties of LbL membranes in highly osmotic solutions.

The stability of LbL-modified membranes in a harsh acidic environment was investigated to identify the potential of LbL membranes for use in acidic filtration tasks, taking $\mathrm{H}_{3} \mathrm{PO}_{4}$ as an example, due to its direct scarcity [34]. The change in performance of the LbL-modified membrane when exposed and during permeation of $\mathrm{H}_{3} \mathrm{PO}_{4}$ was investigated. This approach allows the prediction of potential applications in industrial processes and also highlights the need to further fine tune the membranes for acid separation applications.

\section{Materials and Methods}

Polyethersulfone (PES)- and sulfonated polyethersulfone (sPES)-based hollow fiber UF membranes with an inner diameter of $0.8 \mathrm{~mm}$ were provided by Pentair (Enschede, The Netherlands). The properties of the untreated membranes are shown in Table 1. Both membranes are negatively charged at a neutral $\mathrm{pH}$ [14]. Due to the sulfonate groups, the negative charge of the sPES membrane is significantly higher at a neutral $\mathrm{pH}$. However, the $\zeta$-potential of the sPES increases with decreasing $\mathrm{pH}$. In contrast, the charge of the PES remains stable over a wide $\mathrm{pH}$ range (3-6.5).

Table 1. Properties of virgin membranes [14].

\begin{tabular}{ccccc}
\hline & $\begin{array}{c}\text { Permeability } \\
\left(\mathbf{L} / \mathbf{m}^{2} / \mathbf{h} / \mathbf{b a r}\right)\end{array}$ & $\begin{array}{c}\mathbf{M g S O}_{4} \\
\text { Retention } \mathbf{( \% )}\end{array}$ & $\begin{array}{c}\text { MWCO } \\
(\mathbf{k D a})\end{array}$ & $\begin{array}{c}\zeta \text {-potential } \\
\mathbf{( m V )}\end{array}$ \\
\hline PES & $1^{\prime} 100$ & - & 100 & -13 \\
sPES & 80 & 22 & 10 & -19 \\
\hline
\end{tabular}

\subsection{Module Preparation and Membrane Coating Procedure}

The membranes were potted in modules containing either one or ten fibers. Each hollow fiber had an inner diameter of $0.8 \mathrm{~mm}$, and a length of $300 \mathrm{~mm}$. This resulted in total membrane surfaces of $7.5 \mathrm{~cm}^{2}$ and $75 \mathrm{~cm}^{2}$ respectively. The single hollow fibre modules were built by gluing one hollow fiber membrane into a polyurethane tube with an inner diameter of $4 \mathrm{~mm}$ using polyurethane glue. The ten-fiber modules were built using a PVC tube with an inner diameter of $10 \mathrm{~mm}$, using polyurethane glue.

\subsection{Layer-by-Layer Coating}

Before LbL assembly, the already-potted membranes were soaked in deionized water $(1-3 \mu \mathrm{S} / \mathrm{cm})$ for at least $24 \mathrm{~h}$. Afterwards, the modules were rinsed with deionized water for at least one hour, applying a flow rate of $1 \mathrm{~L} / \mathrm{h} /$ fibre. No pressure was applied. In the next step, the membranes were modified via LbL coating using PES.

Considering the negative charge of the membranes at a neutral $\mathrm{pH}$, the first $\mathrm{PE}$ applied is a positively charged poly(diallyldimethylammonium chloride) (PDADMAC), with a molecular weight of $400-500 \mathrm{kDa}$ in a $20 \%$ solution. This chemical, as well as all other chemicals, was purchased from Sigma-Aldrich (Buchs, Switzerland). The positive layer was followed by negatively charged 
polysodiumstyrenesulfonate (PSS), with a molecular weight of $1000 \mathrm{kDa}$, in a $25 \%$ solution. Both PEs were diluted to $1 \mathrm{~g} / \mathrm{L}$ in 0.5 molar sodium chloride solution prepared from salt available at $>99 \%$ purity.

The PEs were applied using a dead-end filtration mode at a constant pressure of 3 bar (Figure 1). The coating unit consisted of three vessels with tubing for PDADMAC, PSS and demineralized water. The PE are deposited in an alternating manner on the membrane. During this step, the unit is run in dead-end mode. Between each deposition step, the membranes were rinsed with deionized water for at least $15 \mathrm{~min}$ and a flow rate of $1 \mathrm{~L} / \mathrm{h} /$ fibre in cross flow mode. The conductivity of the rinsing water was measured in regular intervals using a GMH 3451 from Greisinger (Regenstauf, Germany). Rinsing was performed until a conductivity of below $3 \mu \mathrm{S} / \mathrm{cm}$ was reached and before the next coating step was carried out. The permeate side was also rinsed with demineralized water. The procedure was repeated until 4 or 8 bi-layers were deposited. A bi-layer consists of one positive and one negative PE layer.

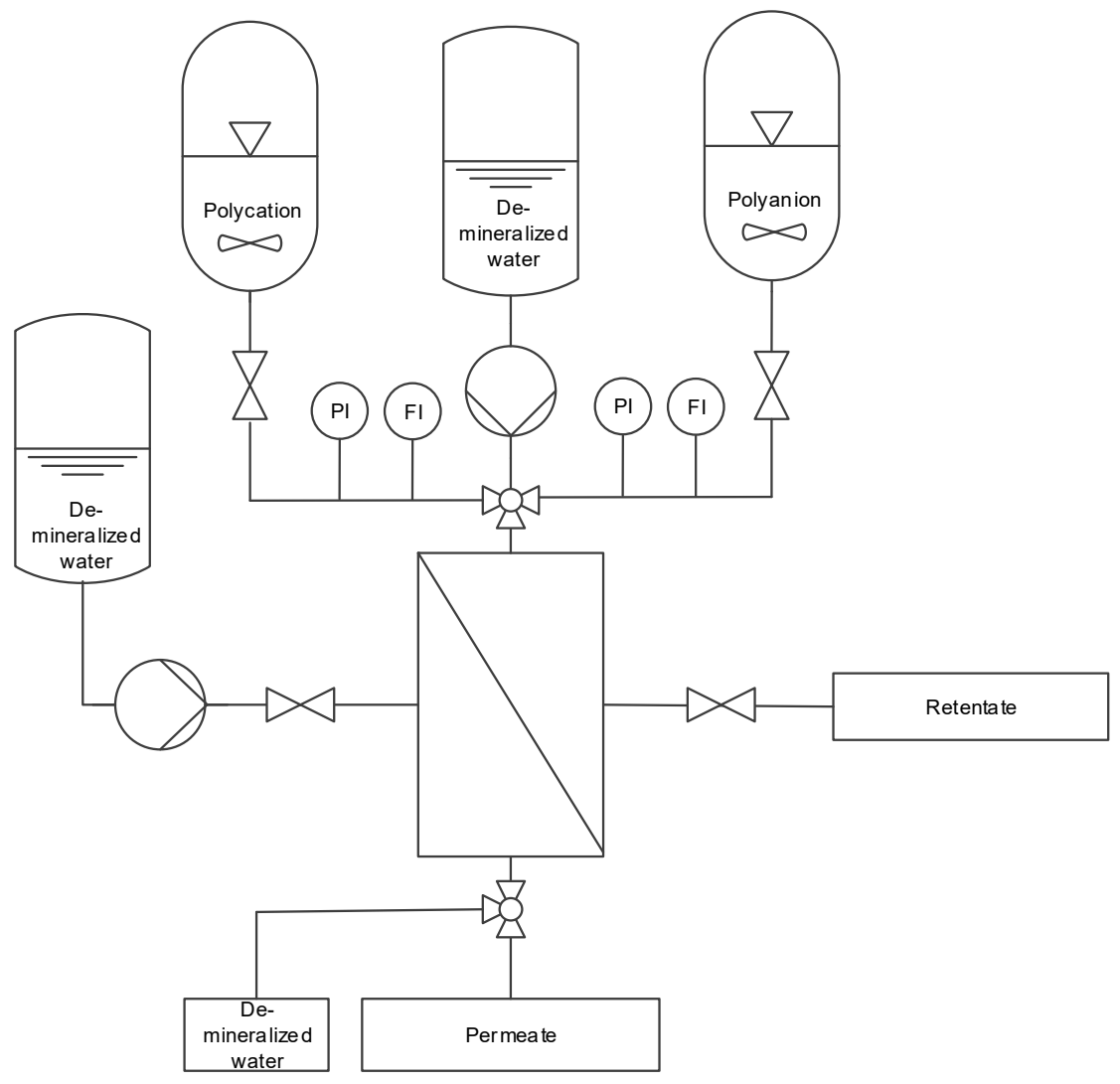

Figure 1. Flowchart of the coating process.

Assuming that the PE is totally retained due to the pore size of the membrane, each applied layer can contain, depending on how many PEs are bound to the charged surface, a maximum of $2 \mathrm{~g}$ polyelectrolyte $/ \mathrm{m}^{2}$ membrane area, resulting in a maximum of $4 \mathrm{~g} / \mathrm{m}^{2}$ per bi-layer.

\subsection{Single Hollow Fiber Modules Characterisation}

$\mathrm{Mg}$ retention was used as an indicator of membrane separation performance. As a feed solution, 0.5 molar $\mathrm{Mg}_{2} \mathrm{SO}_{4}$ dissolved in deionized water was used. The solution was produced using $\mathrm{Mg}$ sulfate heptahydrate (>99\% purity). $\mathrm{H}_{3} \mathrm{PO}_{4}(85 \mathrm{wt} \%$ ) was diluted to $15 \mathrm{wt} \%$, corresponding to a $\mathrm{pH}=0.7$. The $\mathrm{pH}$ was measured using a WTW inoLab Multi 9310 IDS pH-meter (Weilheim in Oberbayern, Germany). The following routine was carried out to evaluate the influence of phosphoric acid on the membrane.

1. Measurement of $\mathrm{Mg}$ retention in cross-flow mode at 5 bar of transmembrane pressure (TMP) using a 0.5 molar Mg solution. The flow volume was $80 \mathrm{~mL} / \mathrm{min}$, resulting in a cross-flow velocity 
of $2.65 \mathrm{~m} / \mathrm{s}$. This leads to a Reynolds number $>2300$, and thus, the experiments were carried out at turbulent flow conditions.

2. $\mathrm{H}_{3} \mathrm{PO}_{4}$ treatment (either (a) or (b) is applied)

(a) The lumen of the membrane is immersed in 15\% phosphoric acid for 2 or $24 \mathrm{~h}$.

(b) Cross-flow filtration at 5 bar was carried out using 15\% phosphoric acid. During the entire treatment, phosphoric acid permeated through the membranes. The cross-flow velocity was $0.8 \mathrm{~m} / \mathrm{s}$. Due to the high viscosity of the phosphoric acid, this resulted in a non-turbulent but laminar flow. Again, this procedure was carried out for 2 and $24 \mathrm{~h}$.

3. Repetition of step (a).

\subsection{Multi Hollow Fiber Module Experiment}

Membrane modules with ten capillaries were tested using a MaxiMem unit from PS Prozesstechnik (Basel, Switzerland). This unit allows the online measurement of the permeate flux during filtration. Again, the retention of $\mathrm{MgSO}_{4}$ was used as a reference to evaluate changes in membrane performance. The following routine was applied for the ten-capillary module experiment:

1. Measurement of Mg retention in cross-flow mode at 3, 5, and 7 bar TMP using 0.5 molar Mg-solution: The volume flow was $1000 \mathrm{~mL} / \mathrm{min}$, resulting in a cross-flow velocity of $3.32 \mathrm{~m} / \mathrm{s}$. This leads to a Reynolds number of approximately 3000 . Thus, the experiments were carried out in a turbulent flow.

2. $\mathrm{H}_{3} \mathrm{PO}_{4}$ filtration for two hours: Cross-flow filtration at 3, 5 and 7 bar was carried out using $15 \%$ phosphoric acid. During the entire treatment, phosphoric acid permeated through the membranes. Again, the cross-flow velocity was $3.32 \mathrm{~m} / \mathrm{s}$.

3. The membrane was rinsed with deionized water until a neutral $\mathrm{pH}$ was reached.

4. Measurement of $\mathrm{Mg}$ retention in cross-flow mode at 3, 5, and 7 bar TMP using 0.5 molar Mg-solution

5. $\mathrm{H}_{3} \mathrm{PO}_{4}$ filtration as described in step (b), for another $22 \mathrm{~h}$, hence in total $24 \mathrm{~h}$ of acidic filtration was applied.

6. The membrane was rinsed with deionized water until a neutral $\mathrm{pH}$ was reached.

7. Measurement of $\mathrm{Mg}$ retention in cross-flow mode at 3, 5, and 7 bar TMP using 0.5 molar Mg-solution.

\subsection{Analytical Procedure}

The $\mathrm{Mg}$ concentration of the samples was determined via triplicate analysis using ionic coupled plasma with optical emission spectroscopy (ICPOES) at a power of $1400 \mathrm{~W}$ (coolant flow: $13 \mathrm{~L} / \mathrm{min}$, auxiliary flow: $1 \mathrm{~L} / \mathrm{min}$, nebulizer flow: $0.75 \mathrm{~L} / \mathrm{min}$, Spectroblue SOP, Spectro Analytical Instruments, Kleve, Germany). The samples were diluted with 0.5 molar $\mathrm{HNO}_{3}$. Scanning electron microscopy (SEM) images were captured using a GeminiSEM from Zeiss (Jena, Germany). The membranes were broken in liquid nitrogen, dried, and sputter-coated with gold before imaging.

\section{Results and Discussion}

\subsection{Evaluation of Membrane Permeability}

Prior to any acidic treatment, the pure water permeability of all tested membranes was analyzed, which is summarized in Table 2. For all membranes, the permeability decreased by over $85 \%$. The highest permeabilties were observed for the PES(PDADMAC/ PSS $)_{4}$ membrane (17 L/( $\mathrm{m}^{2} \mathrm{~h}$ bar)), and the lowest for the sPES(PDADMAC/PSS) 8 membrane. With a view on the initial flux of the bare membrane, the decrease was more evident for the PES membrane (98-99\%) (Table 2). The decrease in permeability can be related to the closing of the pores (layer-dominated regime) or just decreasing the pore size (pore-dominated regime) [14]. The resistance of the membrane and hence also the permeability is influenced by this [13]. Yet, after coating, the difference in permeability for the four LbL membrane types is marginal. The permeabilities are similar to the ones reported by de Grooth et al. [14], 
for PES and sPES membranes. In other studies, higher permeabilities up to $40 \mathrm{~L} /\left(\mathrm{m}^{2} \mathrm{~h}\right.$ bar) were reported [13]. However, comparing LbL membrane performances is difficult, when the membranes are not coated exactly in the same way. Minor changes in the coating solution can have major influences on the membrane behavior. Nevertheless, this study will mainly focus on the influence of highly acidic feed solutions with a high ionic strength, as well as influence of the operating parameters.

Table 2. Permeability of coated membranes.

\begin{tabular}{ccc}
\hline & Permeability $\left(\mathbf{L} / \mathbf{m}^{\mathbf{2}} / \mathbf{h} / \mathbf{b a r}\right)$ & Decrease Compared to Virgin Membrane (\%) \\
\hline PES uncoated & $1^{\prime} 100$ & - \\
sPES uncoated & 80 & - \\
PES(PDADMAC/PSS) & 17 & 98 \\
PES(PDADMAC/PSS) & 15 & 99 \\
sPES(PDADMAC/PSS) & 10 & 87 \\
sPES(PDADMAC/PSS) & 7 & 91 \\
\hline
\end{tabular}

\subsection{Membrane Immersion in Phosphoric Acid Versus Filtration of Phosphoric Acid}

During the first set of experiments, single fiber modules were tested. First, the lumen of the LbL modified membranes was immersed in 15\% phosphoric acid. This concertation was chosen as it is close to real applications, e.g., during P recovery from sewage sludge ash. The results can be seen in Figure 2. As expected, the $\mathrm{Mg}$ retention before immersion was significantly increased for all modified membranes, in comparison to the unmodified membranes. $\mathrm{MgSO}_{4}$ retention can be found in Table 1 for the unmodified sPES and PES.

Each support membrane (PES and sPES) was coated with four or eight bi-layers of PE and each $\mathrm{H}_{3} \mathrm{PO}_{4}$ treatment was carried out in triplicate. For each experiment, a new module was used. Before immersing the lumen in $15 \% \mathrm{H}_{3} \mathrm{PO}_{4}$ solution for $2 \mathrm{~h}$ and $24 \mathrm{~h}, \mathrm{Mg}$ retention was measured. After $2 \mathrm{~h}$ and $24 \mathrm{~h}$, each membrane was rinsed with deionized water until neutral $\mathrm{pH}$ was reached. $\mathrm{The} \mathrm{Mg}$ retention was measured again and compared to the initial retention value.

The retention values for the membranes with the PES support layer were only marginally influenced by the acidic treatment. Over the time range of $24 \mathrm{~h}$, the retention stayed almost constant. However, it has to be noted that for both layer variations (four and eight bi-layers), a slight decrease, of $2-10 \%$ in retention was observed after $2 \mathrm{~h}$ compared to the initial value. Several explanations can be found to describe this behavior: change in charge compensation, new alignment of the layers or decomposition of the layer $[33,35,36]$. In any case, it can be concluded that the influence of $\mathrm{H}_{3} \mathrm{PO}_{4}$ on both membranes (four and eight bi-layers) is negligible.

The membranes coated on a sPES support show a different picture. Again, a small change in retention was observed after $2 \mathrm{~h}$ of immersion, but a further decrease in retention was observed after $24 \mathrm{~h}$. The retention decreased linearly with time for the sPES(PDADMAC/ PSS) 4 membrane until only $20 \%$ of $\mathrm{Mg}$ retention remained after $24 \mathrm{~h}$. The decrease for sPES(PDADMAC/ PSS) 8 was less distinct than after $2 \mathrm{~h}$, but still decreased down to $35 \% \mathrm{Mg}$ retention from $65 \%$ initially. This might indicate that the number of layers, and therefore also the mass of PE on the membrane, plays a role in the chemical resistance towards an acidic environment.

The influence of the support membranes during backwashing cycles has already been shown by de Grooth et al. [14]. Here sPES membranes showed higher mechanical resistance towards the backwashing, which was ascribed to the higher charge of the sulfonated membrane. The layers assembled on the PES membrane altered during the backwashing cycle, resulting in decreased retention values [14]. During exposure to sodium hypochlorite, sPES membranes showed a great chemical tolerance towards the treatment [14]. No data on chemical resistance for PES nor sPES as a membrane support is known when exposed to low $\mathrm{pH}$. Researchers have instead focused on the influence of PE on the support membrane properties, e.g., the mechanical strength [32], the ionic strength during coating [37] or the influence of PE pairing [38]. 

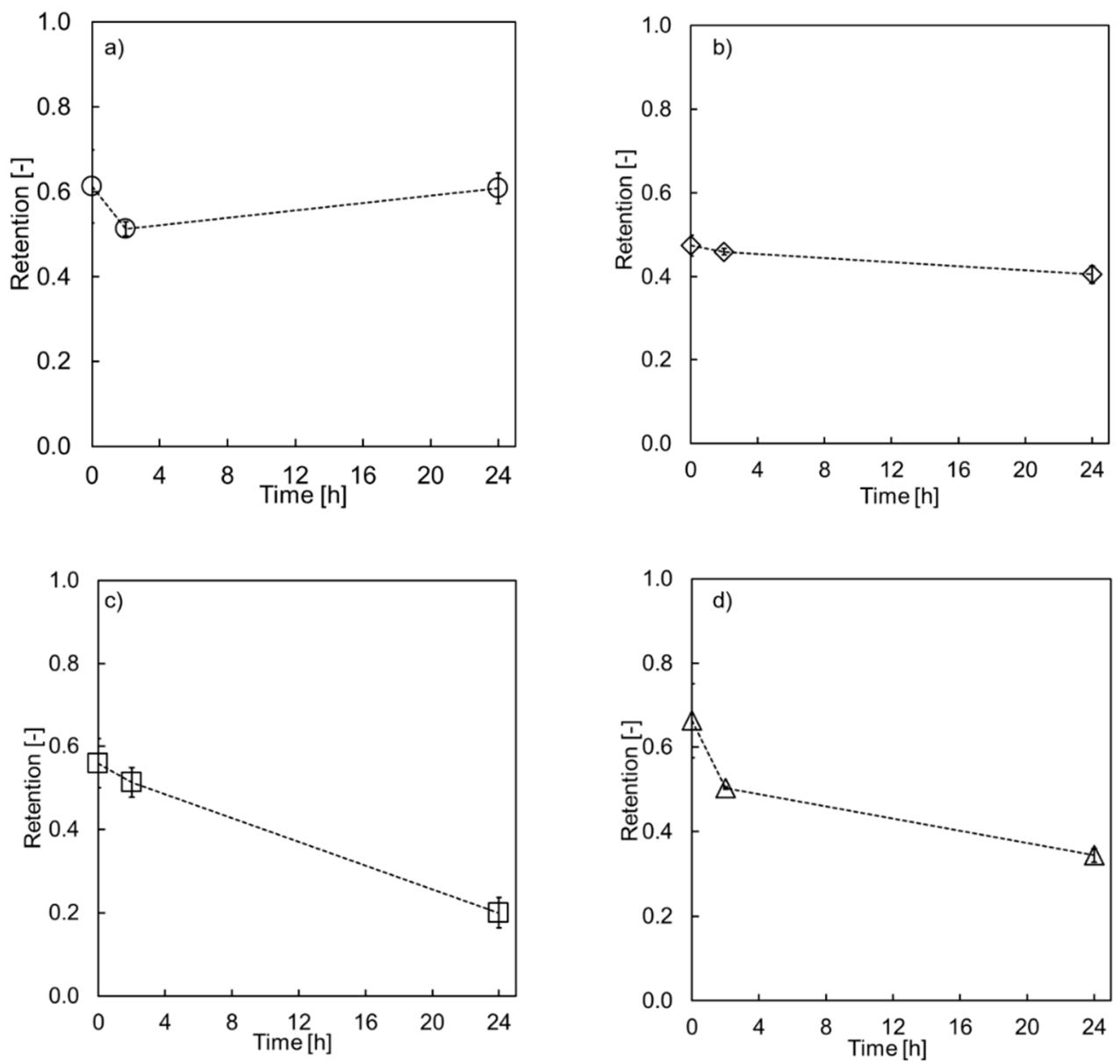

Figure 2. $\mathrm{Mg}$ retention values of immersed membranes in $15 \% \mathrm{H}_{3} \mathrm{PO}_{4}$ (a) PES (PDADMAC/PSS) ${ }_{4}$, (b) PES (PDADMAC/PSS) 8 (c) sPES (PDADMAC/PSS) (d) $_{4}$ sPES (PDADMAC/PSS) 8 as a function of immersion time.

The results presented in this study indicate that the bond between sPES and the PDADAMC/PSS multilayer decreases when exposed to an acidic environment. However, immersing the lumen in $\mathrm{H}_{3} \mathrm{PO}_{4}$ is an extreme situation that usually only occurs during process interruptions. Hence, in the next step, filtration of $\mathrm{H}_{3} \mathrm{PO}_{4}$ was performed. Here, pressure was applied to the membrane as well as shear forces due to the cross-flow through the membrane.

A new set of membranes, equal to the ones tested in the first experimental phase, were prepared for the filtration of $\mathrm{H}_{3} \mathrm{PO}_{4}$. Instead of the former described immersion of the membranes in $\mathrm{H}_{3} \mathrm{PO}_{4}$, filtration was conducted at 5 bar for either 2 or $24 \mathrm{~h}$. Mg retention was measured and used as an indicator for membrane integrity. The results shown in Figure 3 are very similar for all four membrane variations, showing almost no decreases in $\mathrm{Mg}$ retention. Neither the support layer nor the number of PE layers plays a role any longer. Again, slight changes after $2 \mathrm{~h}$ of filtration were observed, which can be ascribed to the membranes adjusting to the acidic conditions.

The applied pressure and cross-flow seemed to lead to a higher acidic resistance during filtration. The bonding of the PE to the substrate of sPES(PDADMAC/ PSS) $_{4} / \mathrm{sPES}$ (PDADMAC/PSS) 8 exposed to the acid may weaken during immersion as seen in Figure 2. The rinsing step after immersing washes the PE out of the lumen, and therefore subsequently measured $\mathrm{Mg}$ retention decreases. The longer the membrane is in contact with the acid, the more severe the damage resulting in decreased retention. After $24 \mathrm{~h}$, similar retention values as for the bare membrane were reached. $\zeta$-potential measurements showed that the charge for the sPES-based membrane becomes less negative with decreasing $\mathrm{pH}$. This was shown for a $\mathrm{pH}$ range between 5.75-7.75 [14] and for a $\mathrm{pH}$ range between 2-6 [23]. At $\mathrm{pH}=0.6$, 
the membrane could even be less negatively charged as the sulfuric groups were no longer negatively charged. Hence, the former intrinsic charge compensation towards the support membrane was not stable anymore. Part of the layer will detach and wash out during rinsing with deionized water, leading to a non-dense and defective membrane. It seems that the stability of the LbL membrane is highly influenced by the pressure and cross-flow velocity during filtration.
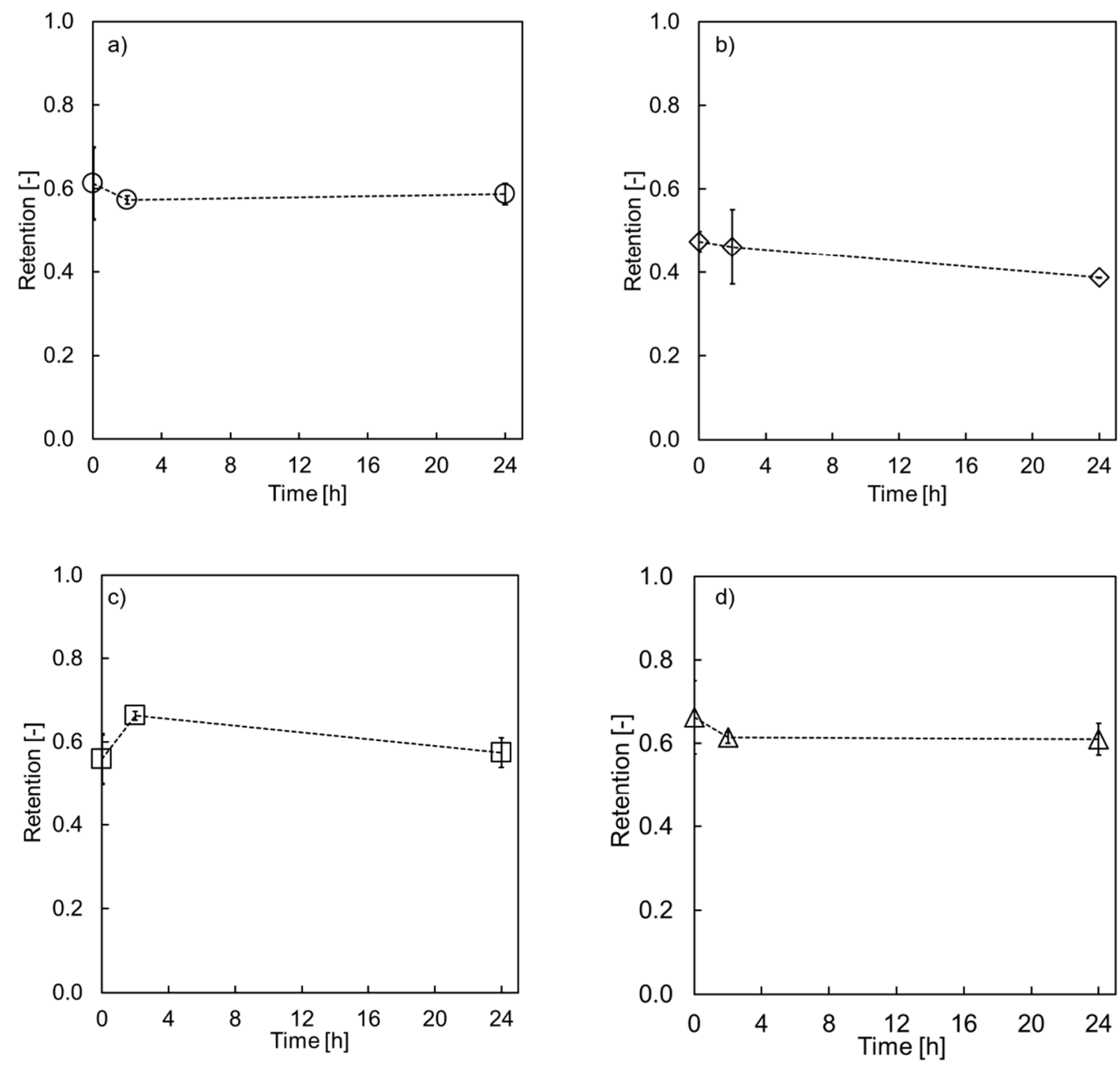

Figure 3. $\mathrm{Mg}$ retention values of membranes after filtering a $15 \% \mathrm{H}_{3} \mathrm{PO}_{4}$ solution at $\mathrm{TMP}=5 \mathrm{bar}, \mathrm{v}=2.65$ $\mathrm{m} / \mathrm{s}\left(\operatorname{Re}>2^{\prime} 300 \text { ) for (a) PES (PDADMAC/PSS) }{ }_{4}, \text { (b) PES (PDADMAC/PSS }\right)_{8}$, (c) sPES (PDADMAC/PSS) ${ }_{4}$, (d) sPES (PDADMAC/PSS) 8 as a function of $\mathrm{H}_{3} \mathrm{PO}_{4}$ filtration time.

Other studies have shown that morphological changes caused by high ionic strength salt solutions can be reversed when rinsed with deionized water [33]. However, nothing has been reported on the filtration properties. Menne [30] showed a decrease in permeability after treating a PDADMAC/PSS system on a ceramic support membrane. The membranes tested in our study seem to alter irreversibly during the acidic treatment. This is supported by the SEM images in Figure 4, which are discussed in the next section. 

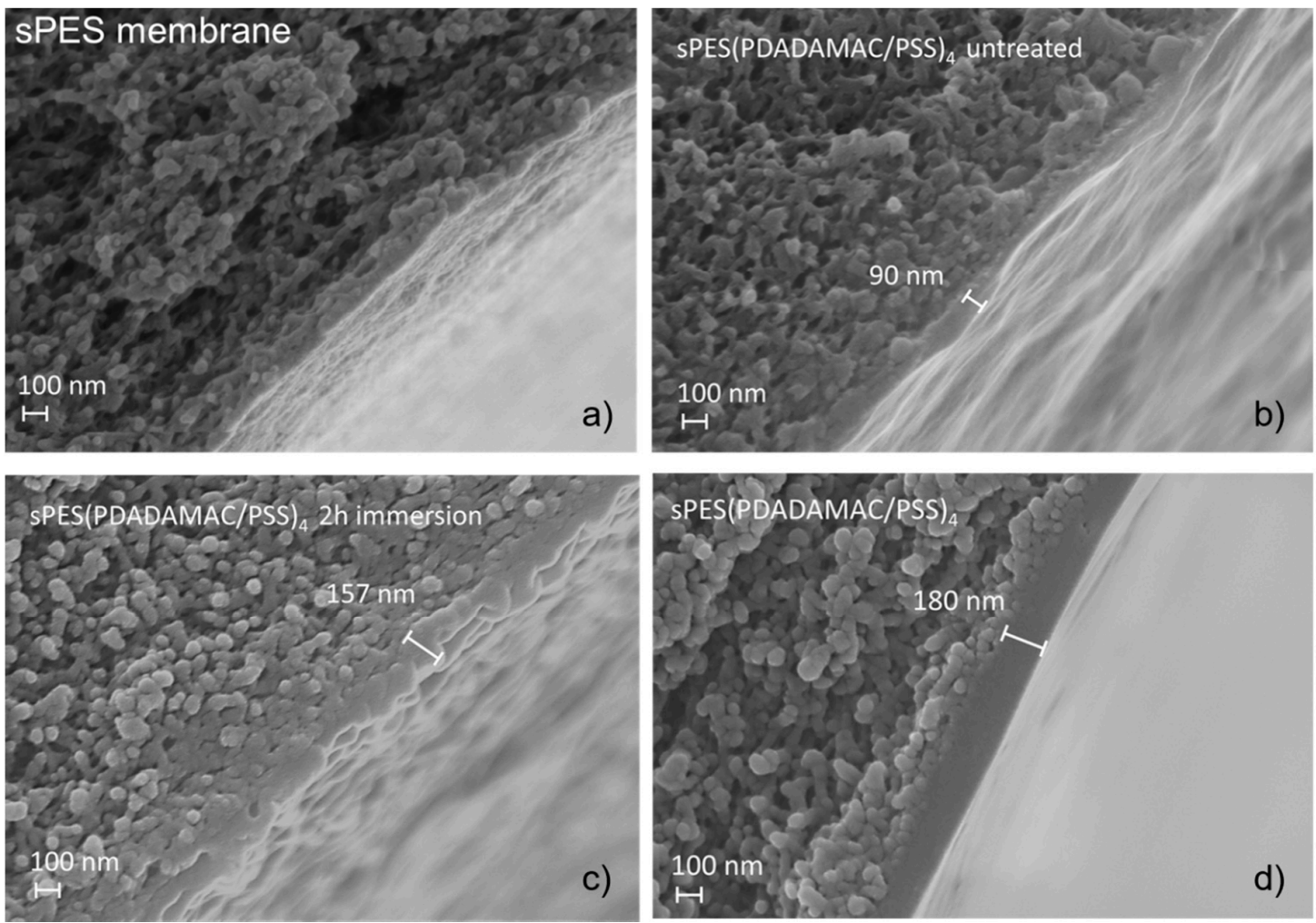

Figure 4. SEM images of sPES (sulfonated polyethersulfone) membranes; (a) uncoated membrane,

(b) membrane after LbL coating, (c) coated LbL membrane after immersing for $2 \mathrm{~h}$ in phosphoric acid,

(d) coated LbL membrane after $2 \mathrm{~h}$ of phosphoric acid filtration.

\subsection{Scanning Electron Microscopy Analysis of the Modified Membranes}

The alteration of the LbL membrane was further examined by the example of sPES membranes using scanning electron microscopy. The performance of the sPES membrane changed depending if the membrane was just immersed in the acid without pressure and cross flow velocity or if filtration took place. SEM pictures were taken of (A) the bare sPES membrane; (B) the sPES(PDADMAC/ PSS) membrane directly after coating; (C) the sPES(PDADMAC/ PSS) $)_{4}$ membrane after immersing into $\mathrm{H}_{3} \mathrm{PO}_{4}$ for $2 \mathrm{~h}$; (D) sPES(PDADMAC/ PSS) ${ }_{4}$ after filtering $\mathrm{H}_{3} \mathrm{PO}_{4}$ for $2 \mathrm{~h}$. The image taken of the membrane after deposition of four bi-layers shows a membrane thickness of approximately $90 \mathrm{~nm}$. This is in line with the results from Menne et al. [13], who obtained $140 \mathrm{~nm}$ for eight bi-layers and $70 \mathrm{~nm}$ for one bi-layer applying a dynamic coating.

Membranes coated with static coating have thinner bi-layers [36,39]. This indicates that in addition to the entropic forces mainly leading to the PE multilayer build up, additional binding regimes take place, leading to an increase in thickness during dynamic coating, as applied in this study. A deeper penetration into the membrane due to the applied pressure during coating could be a reason for thicker layers [13]. A potential explanation is partial entanglement of PE with the pores of the substrate membrane due to the applied mechanical forces. The "trapped" PE may not be washed out during the rinsing step with deionized water, allowing more PE to bind to the membrane, resulting in a thicker layer.

After immersing the membrane in $\mathrm{H}_{3} \mathrm{PO}_{4}$ for two hours, the layer was more swollen compared to the untreated sample (Figure 4C). The thickness of the immersed membrane was around $160 \mathrm{~nm}$. The SEM picture indicates that the layer was no longer dense but rather porous like the UF substrate. The surface layer was rough and not homogeneous. This may be a consequence of the acidic treatment. The deteriorated morphology after immersing the membrane supports the data obtained from the 
experiments, showing lower retentions for Mg. Immersing the membrane in $\mathrm{H}_{3} \mathrm{PO}_{4}$ led to an altered membrane, which shows similar filtration characteristics as the bare UF membrane (Figure 2).

The image in Figure $4 \mathrm{D}$ shows the sPES(PDADMAC/ PSS) ${ }_{4}$ membrane after filtering $\mathrm{H}_{3} \mathrm{PO}_{4}$ for two hours. It can be seen that the PEM is thicker compared to the untreated layer $(180 \mathrm{~nm})$. However, the most significant features are the homogeneous structure and smooth surface of the layer. The surface is straightened and no defects can be observed. The influence of the cross-flow and the applied pressure most likely lead to this advanced surface of the membrane. Thus, it was shown that pressure and cross-flow velocity applied to the membrane are important factors to consider with respect to membrane alteration.

The SEM images support the hypothesis of severe damage to the PE multilayer during immersion and an intact layer during the filtration experiment. Pressure and cross-flow velocity applied during filtration seem to stabilize the membrane, and if a sPES membrane is used as a support, this is crucial to maintain an intact membrane (Figures 2 and 3). Immersing the membrane into $\mathrm{H}_{3} \mathrm{PO}_{4}$ occurs usually only during an operational failure of the filtration process. Therefore, it can be concluded that in a regular working operation, the membrane performance is only slightly decreased for both support membrane types, after a steady state has been reached.

\subsection{Influence of High Ionic Strength on the Mg Retention Using LbL Membranes}

A study carried out by Bargeman [40] addresses the issue of membrane characterization only conducted for low salt concentrations, which does not reflect most of the industrial applications. In this study, retention values for a $500 \mathrm{mM} \mathrm{MgSO}_{4}$ feed solution are shown. The retention values range from 48 to $78 \%$, which is rather low when compared to known data from the literature. Menne et al. [13] reached $80-90 \% \mathrm{MgSO}_{4}$ retention for a sPES based support layer assembled with four bi-layered PDADMAC/PSS. De Grooth et al. [14] reached retention values of up to $84 \%$, applying a PES based membrane with 2 bi-layers PDADMAC/PSS. However, these results were obtained using a $5 \mathrm{mM}$ $\mathrm{MgSO}_{4}$ solution, whereas the results presented here show the retention for $500 \mathrm{mM} \mathrm{MgSO}_{4}$ solution, which is much closer to the salinity of industrial applications.

Several properties of the LbL led to decreased retention when filtering high osmotic salt solutions. Bargeman et al. [41] showed that as a consequence of an increase in ionic strength, the active layer swells, and hence, the retention values decrease due to increasing convective transport. Another important effect is the shielding of the membrane considering the high ionic strength of the feed solution. The counterions screen the membrane, and the repulsion effect for the coions is decreased $[14,42,43]$.

In the next step, the possibility of increasing $\mathrm{Mg}$ retention values for LbL membranes by adjusting operating parameters is studied. In NF, retention values can be increased by increasing the convective water flow. This is achieved by increasing the TMP, thus increasing the overall transmembrane water flux. With increasing water flux, the share of mass transported by diffusion is decreased and hence plays only a minor role. Therefore, in the next step, a higher TMP was applied but also a higher cross-flow velocity influencing the membrane performance during acidic filtration. An increased cross-flow velocity can lead to an optimized transport regime at the membrane surface, e.g., by decreasing concentration polarization. The difference between the retention values of $5 \mathrm{mM}$ and $500 \mathrm{mM} \mathrm{MgSO} 4$ was tested at a TMP of 5 bar. The results can be seen in Table 3 and Figure 5 for a PES(PDADMAC/PSS) $)_{4}$.

Table 3. Permeability of coated membranes.

\begin{tabular}{cc}
\hline $\mathrm{MgSO}_{\mathbf{4}}$ Feed Concentration (mM) & Retention (-) \\
\hline 5 & 0.90 \\
500 & 0.77 \\
\hline
\end{tabular}



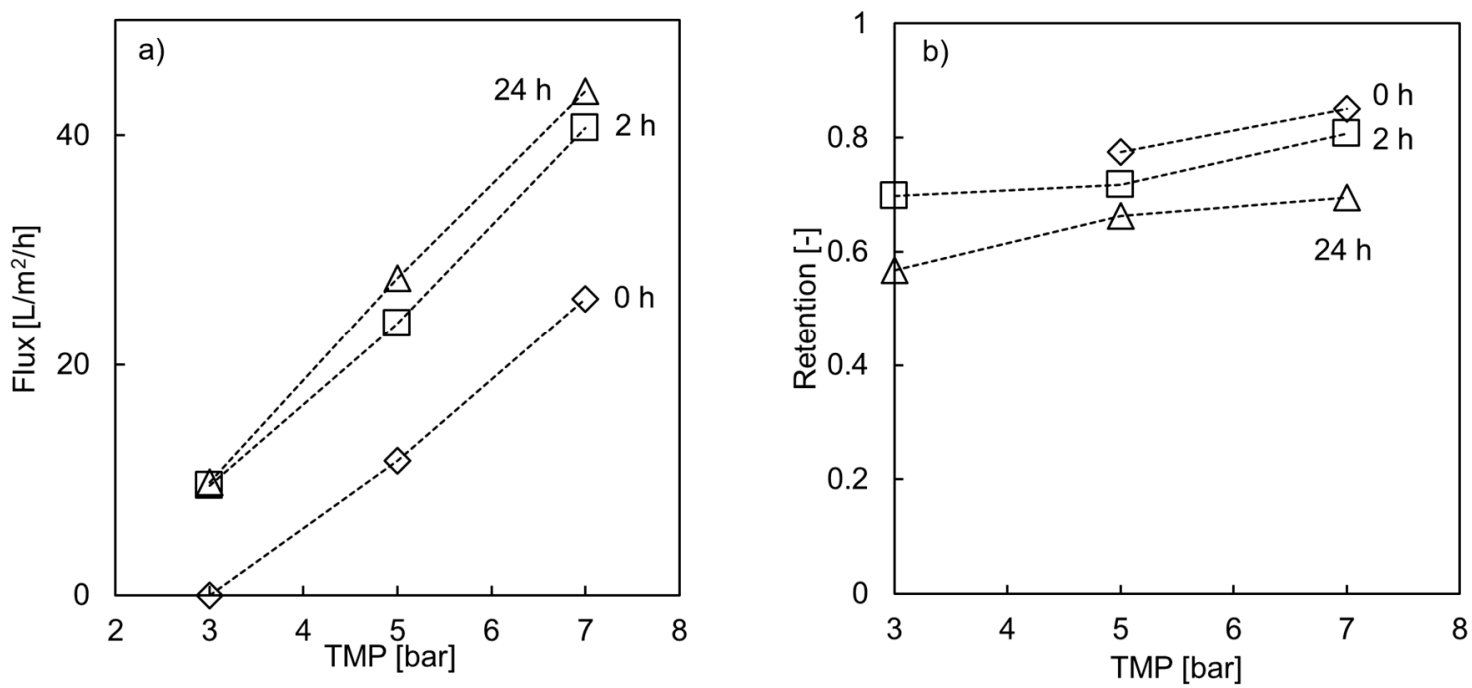

Figure 5. (a) Flux and (b) $\mathrm{Mg}$ retention for $500 \mathrm{mM} \mathrm{MgSO}_{4}$ feed solution for sPES (PDADMAC/PSS) 4 as a function of TMP before and after filtering a $15 \% \mathrm{H}_{3} \mathrm{PO}_{4}$ solution for two and $24 \mathrm{~h}\left(\mathrm{Re}>2^{\prime} 300\right)$.

The retention values for a $5 \mathrm{mM} \mathrm{MgSO}_{4}$ feed solution were in the same range as the above-mentioned studies $[13,14]$. The retention values for a $500 \mathrm{mM}$ solution could be increased to $77 \%$ at 5 bar, probably caused by the higher cross-flow velocity. By increasing the pressure to $7 \mathrm{bar}, 85 \% \mathrm{Mg}$ retention was reached. Due to a higher flux (Figure 5B) and therefore higher convective flows, the diffusive flow becomes smaller in relation, thus increasing the retention for $\mathrm{Mg}$. It can be understood that even though many properties of an LbL membrane are defined by the chosen PE, coating conditions and feed solution, operational adjustment can also lead to an increased membrane performance. Phenomena typically influencing membrane performance such as concentration polarization and steric effects are decreased by optimized process parameters.

The influence of $\mathrm{H}_{3} \mathrm{PO}_{4}$ on flux and $\mathrm{Mg}$ retention as a function of TMP is shown in Figure 5 for a sPES(PDADMAC/ PSS) ${ }_{4}$ module with ten hollow fiber membranes. Through optimization of operating conditions, $\mathrm{Mg}$ retention was increased to $85 \%$ at 7 bar. It was not possible to observe a permeate flow at 3 bar at the beginning of the experiment $(0 \mathrm{~h})$, and hence also no $\mathrm{Mg}$ retention could be measured. This is due to the osmotic pressure of the bulk solution. According to the Van 't Hoff equation for osmotic pressure $\Pi$ (Equation 1) [44] and taking the water hold up of the membrane unit into account, the osmotic pressure for the feed solution is between 8.5-12 bar. Which is in line with literature values calculated by OLI Stream Analyzer [45]. Assuming a Mg retention of 70\%, a pressure difference between 5.9-8.5 bar needs to be overcome. At a TMP of 5 bar, retention and flux values were able to be recorded at the beginning of the experimental time $(0 \mathrm{~h})$.

$$
\Pi=-\left(\frac{n_{s}}{V}\right) R T
$$

where $\Pi$ osmotic pressure, n number of moles of species, $V$ volume of solvent, $R$ gas constant, $T$ temperature.

After two hours of acidic filtration, the retention values decreased slightly compared to the initial measurement. At 7 bar, a Mg retention value of $80 \%$ was recorded. After two hours of acidic filtration, a retention value of $70 \%$ at 3 bar could be recorded. This indicates that for LbL-modified membranes, the membrane resistance plays an important role [30]. The ideal permeate flux $V p$ through an uncoated UF membrane is described by the pore-model (Equation (2)) [46]. After modifications, the membrane shows NF properties; therefore, the transport might be better described by the extended NernstPlanck equation [46,47]. However, all of these models do not take into account the special properties of an LbL system. An increased water permeability can be ascribed to the swelling of the 
PDADMAC in the membrane $[30,48]$. Another influencing factor is the ion-exchange properties of an LbL membrane $[37,48]$. The osmotic strength of the PE multilayer itself also influences the properties of the membrane [30]. The osmotic strength can be influenced by the $\mathrm{NaCl}$ concentration of the coating solution. For LbL membranes, two forms of bindings can occur, which can be influenced by the ionic strength of the coating solution, and intrinsic and extrinsic charge compensation. Rather dense and thin layers are present if intrinsic charge compensation is the dominating regime, which results in high ion rejection of the membrane. A membrane with mostly extrinsic bound PE has a more open and swollen structure resulting in lower ion rejection [35,36]. Another influencing factor is the ion-exchange properties of an LbL membrane, which is not further discussed in this paper $[37,48]$.

$$
\begin{gathered}
V_{p}=\frac{\dot{m_{p}^{\prime \prime}}}{\rho_{p}}=A \Delta p \\
A=\frac{\varepsilon^{3}}{\eta(1-\varepsilon)^{2} S_{(V)}^{2} 2 \tau \delta}(\text { Carman - Kozeny })
\end{gathered}
$$

where $V_{p}$ permeate flow, $\dot{m}_{p}^{\prime \prime}$ permeate mass flow, $\rho_{p}$ permeate density, $p$ pressure, $\varepsilon$ membrane porosity, $\eta$ dynamic viscosity, $S_{(V)}$ volume specific surface area, $\tau$ tortuosity, $\delta$ membrane thickness.

Before $\mathrm{H}_{3} \mathrm{PO}_{4}$ filtration (at $0 \mathrm{~h}$ ) the pure water flux increases linearly up to $25 \mathrm{~L} /\left(\mathrm{m}^{2} \mathrm{~h}\right.$ ) at 7 bar. After $2 \mathrm{~h}$ of $\mathrm{H}_{3} \mathrm{PO}_{4}$ permeation the pure water flux for a $\mathrm{PPES}(\mathrm{PDADMAC} / \mathrm{PSS})_{4}$ membrane increased to $40 \mathrm{~L} /\left(\mathrm{m}^{2} \mathrm{~h}\right)$ at 7 bar and after $24 \mathrm{~h}$ to $44 \mathrm{~L} /\left(\mathrm{m}^{2} \mathrm{~h}\right)$ (Figure 5$)$, compared to $25 \mathrm{~L} /\left(\mathrm{m}^{2} \mathrm{~h}\right)$ as the initial value at 7 bar. Thus, the membrane is very likely to have altered due to the ion-exchange process during filtration, which leads to increased flux and decreased retention $[37,48]$. The rate of change in flux after $2 \mathrm{~h}$ is higher than between 2 and $24 \mathrm{~h}$. This indicates that a steady state is reached.

\section{Conclusions}

To conclude, layer-by-layer modified membranes are applicable in a harsh acidic environment. This was shown for two different support layers: PES and sPES. The membranes were tested in two types of configurations during exposure to acidic conditions: Mg retention decreases slightly when applying pressure and cross-flow, but a steady state can be reached. However, if no pressure is applied, as during immersion, not all support layer materials are suitable. For sPES-based membranes, $\mathrm{Mg}$ retention decreases by over $40 \%$ during immersion. In contrast, $\mathrm{Mg}$ retention decreased only slightly if the layer was coated onto the PES support. To guarantee a process with an intact membrane and constant retention values, process interruption, in which the membrane is soaked in $\mathrm{H}_{3} \mathrm{PO}_{4}$ without pressure and cross flow, must be avoided.

Retention values for high-ionic-strength solutions are not as high as for solutions with a low ionic strength. However, by adjusting process parameters, such as cross-flow velocity and TMP, Mg retention values of up to $85 \%$ can be reached even for a $500 \mathrm{mM} \mathrm{MgSO}_{4}$ solution.

The main finding of this study is the possibility of tailoring LbL membranes to achieve an efficient and environmentally friendly solution for $\mathrm{H}_{3} \mathrm{PO}_{4}$ recovery and acid recovery in general. The next steps will be to apply LbL membranes to applications such as spent $\mathrm{H}_{3} \mathrm{PO}_{4}$ recovery or $\mathrm{P}$ recovery from sewage sludge.

Author Contributions: Conceptualization, K.R. and B.M.; methodology, K.R. and B.M.; validation, K.R., B.M. and J.K.; investigation, K.R. and B.M.; writing-original draft preparation, K.R.; writing-review and editing, B.M., J.K., T.W. and M.W.; visualization, X.X.; supervision, J.K., M.W., T.W.; project administration, K.R.; funding acquisition, K.R., T.W. All authors have read and agreed to the published version of the manuscript.

Funding: The work presented in this paper was financially supported by Swiss National Science Foundation and the Commission for Innovation and Technology: Bridge - Proof of Concept for the funding under Grant agreement 20B1-1177283.

Conflicts of Interest: The authors declare no conflict of interest. 


\section{References}

1. Agrawal, A.; Sahu, K. An overview of the recovery of acid from spent acidic solutions from steel and electroplating industries. J. Hazard. Mater. 2009, 171, 61-75. [CrossRef]

2. Regel-Rosocka, M. A review on methods of regeneration of spent pickling solutions from steel processing. J. Hazard. Mater. 2010, 177, 57-69. [CrossRef]

3. González, M.; Navarro, R.; Saucedo, I.; Avila, M.; Revilla, J.; Bouchard, C. Purification of phosphoric acid solutions by reverse osmosis and nanofiltration. Desalination 2002, 147, 315-320. [CrossRef]

4. Sun, T.R.; Ottosen, L.M.; Solismaa, S.; Kirkelund, G.M. Effect of pulse current on acidification and removal of $\mathrm{Cu}, \mathrm{Cd}$, and As during suspended electrodialytic soil remediation. Electrochim. Acta 2013, 107, 187-193. [CrossRef]

5. European Commission. Integrated Pollution Prevention and Control Large Volume Inorganic Chemicals-Ammonia, Acids and Fertilisers I; European Commission: Bruxelles, Belgium, 2007.

6. de Boer, M.A.; Wolzak, L.; Slootweg, J.C. Phopshorus Recovery and Recycling - Phosphorus: Reserves, Production, and Applications; Springer Nature: Singapore, 2019.

7. Tayibi, H.; Choura, M.; López, F.A.; Alguacil, F.J.; López-Delgado, A. Environmental impact and management of phosphogypsum. J. Environ. Manag. 2009, 90, 2377-2386. [CrossRef] [PubMed]

8. Tanninen, J. Long-term acid resistance and selectivity of NF membranes in very acidic conditions. J. Membr. Sci. 2004, 240, 11-18. [CrossRef]

9. Niewersch, C. Nanofiltration for Phosphorus Recycling from Sewage Sludge. Ph.D. Thesis, RWTH Aachen University, Aachen, Germany, 2013.

10. Schütte, T.; Niewersch, C.; Wintgens, T.; Yuce, S. Phosphorus recovery from sewage sludge by nanofiltration in diafiltration mode. J. Membr. Sci. 2015, 480, 74-82. [CrossRef]

11. Blöcher, C.; Niewersch, C.; Melin, T. Phosphorus recovery from sewage sludge with a hybrid process of low pressure wet oxidation and nanofiltration. Water Res. 2012, 46, 2009-2019. [CrossRef]

12. Remmen, K.; Müller, B.; Köser, J.; Wessling, M.; Wintgens, T. Phosphorus recovery in an acidic environment using layer-by-layer modified membranes. J. Membr. Sci. 2019, 582, 254-263. [CrossRef]

13. Menne, D.; Kamp, J.; Wong, J.E.; Wessling, M. Precise tuning of salt retention of backwashable polyelectrolyte multilayer hollow fiber nanofiltration membranes. J. Membr. Sci. 2016, 499, 396-405. [CrossRef]

14. De Grooth, J.; Haakmeester, B.; Wever, C.; Potreck, J.; De Vos, W.M.; Nijmeijer, K. Long term physical and chemical stability of polyelectrolyte multilayer membranes. J. Membr. Sci. 2015, 489, 153-159. [CrossRef]

15. De Grooth, J.; Oborny, R.; Potreck, J.; Nijmeijer, K.; De Vos, W.M. The role of ionic strength and odd-even effects on the properties of polyelectrolyte multilayer nanofiltration membranes. J. Membr. Sci. 2015, 475, 311-319. [CrossRef]

16. Laakso, T.; Pihlajamäki, A.; Mänttäri, M. Effect of polycation structure on the fabrication of polyelectrolyte multilayer hollow fiber membranes for loose nanofiltration applications. Sep. Purif. Technol. 2018, 194, 141-148. [CrossRef]

17. Joseph, N.; Ahmadiannamini, P.; Jishna, P.S.; Volodin, A.; Vankelecom, I.F. 'Up-scaling' potential for polyelectrolyte multilayer membranes. J. Membr. Sci. 2015, 492, 271-280. [CrossRef]

18. Joseph, N.; Ahmadiannamini, P.; Hoogenboom, R.; Vankelecom, I.F.J. Layer-by-layer preparation of polyelectrolyte multilayer membranes for separation. Polym. Chem. 2014, 5, 1817-1831. [CrossRef]

19. Zhang, G.; Gu, W.; Ji, S.; Liu, Z.; Peng, Y.; Wang, Z. Preparation of polyelectrolyte multilayer membranes by dynamic layer-by-layer process for pervaporation separation of alcohol/water mixtures. J. Membr. Sci. 2006, 280, 727-733. [CrossRef]

20. Cheng, W.; Liu, C.; Tong, T.; Epsztein, R.; Sun, M.; Verduzco, R.; Ma, J.; Elimelech, M. Selective removal of divalent cations by polyelectrolyte multilayer nanofiltration membrane: Role of polyelectrolyte charge, ion size, and ionic strength. J. Membr. Sci. 2018, 559, 98-106. [CrossRef]

21. Cheng, C.; Yaroshchuk, A.; Bruening, M.L. Fundamentals of Selective Ion Transport through Multilayer Polyelectrolyte Membranes. Langmuir 2013, 29, 1885-1892. [CrossRef]

22. Hong, S.U.; Ouyang, L.; Bruening, M.L. Recovery of phosphate using multilayer polyelectrolyte nanofiltration membranes. J. Membr. Sci. 2009, 327, 2-5. [CrossRef] 
23. Paltrinieri, L.; Remmen, K.; Müller, B.; Chu, L.; Köser, J.; Wintgens, T.; Wessling, M.; De Smet, L.; Sudhölter, E.J. Improved phosphoric acid recovery from sewage sludge ash using layer-by-layer modified membranes. J. Membr. Sci. 2019, 587, 117162. [CrossRef]

24. Maza, E.; Tuninetti, J.S.; Politakos, N.; Knoll, W.; Moya, S.E.; Azzaroni, O. pH-responsive ion transport in polyelectrolyte multilayers of poly (diallyldimethylammonium chloride) (PDADMAC) and poly(4-styrenesulfonic acid-co-maleic acid) (PSS-MA) bearing strong- and weak anionic groups. Phys. Chem. Chem. Phys. 2015, 17, 29935-29948. [CrossRef] [PubMed]

25. Xie, A.F.; Granick, S. Weak versus Strong: A Weak Polyacid Embedded within a Multilayer of Strong Polyelectrolytes. J. Am. Chem. Soc. 2001, 123, 3175-3176. [CrossRef]

26. Sui, Z.; Schlenoff, J.B. Phase Separations in pH-Responsive Polyelectrolyte Multilayers: Charge Extrusion versus Charge Expulsion. Langmuir 2004, 20, 6026-6031. [CrossRef] [PubMed]

27. Remmen, K.; Schäfer, R.; Hedwig, S.; Wintgens, T.; Wessling, M.; Lenz, M. Layer-by-layer membrane modification allows scandium recovery by nanofiltration. Environ. Sci. Water Res. Technol. 2019, 5, 1683-1688. [CrossRef]

28. Nehmé, R.; Perrin, C.; Cottet, H.; Blanchin, M.-D.; Fabre, H. Stability of capillaries coated with highly charged polyelectrolyte monolayers and multilayers under various analytical conditions-Application to protein analysis. J. Chromatogr. A 2011, 1218, 3537-3544. [CrossRef] [PubMed]

29. Menne, D.; Uzüm, C.; Koppelmann, A.; Erik, J.; Foeken, C.V.; Borre, F.; Dähne, L.; Laakso, T.; Pihlajamäki, A.; Wessling, M. Regenerable polymer / ceramic hybrid nano fi ltration membrane based on polyelectrolyte assembly by layer-by-layer technique. J. Membr. Sci. 2016, 520, 924-932. [CrossRef]

30. Menne, D. Layer-by-Layer Design of Nanofiltration Membranes. Ph.D. Thesis, RWTH Aachen University, Aachen, Germany, 2017.

31. Gao, C.; Leporatti, S.; Moya, S.E.; Donath, E.; Möhwald, H. Swelling and Shrinking of Polyelectrolyte Microcapsules in Response to Changes in Temperature and Ionic Strength. Chemistry 2003, 9, 915-920. [CrossRef]

32. Frueh, J.; Köhler, R.; Möhwald, H.; Krastev, R. Changes of the Molecular Structure in Polyelectrolyte Multilayers under Stress. Langmuir 2010, 26, 15516-15522. [CrossRef]

33. Irigoyen, J.; Han, L.; Llarena, I.; Mao, Z.; Gao, C.; Moya, S.E. Responsive Polyelectrolyte Multilayers Assembled at High Ionic Strength with an Unusual Collapse at Low Ionic Strength. Macromol. Rapid Commun. 2012, 33, 1964-1969. [CrossRef]

34. European Commission. Towards A Circular Economy: A Zero Waste Programme for Europe; European Commission: Bruxelles, Belgium, 2014.

35. Schlenoff, J.B.; Ly, H.; Li, M. Charge and Mass Balance in Polyelectrolyte Multilayers. J. Am. Chem. Soc. 1998, 120, 7626-7634. [CrossRef]

36. Schlenoff, J.B.; Dubas, S.T. Mechanism of Polyelectrolyte Multilayer Growth: Charge Overcompensation and Distribution. Macromolecules 2001, 34, 592-598. [CrossRef]

37. Kelly, K.D.; Fares, H.; Shaheen, S.A.; Schlenoff, J.B. Intrinsic Properties of Polyelectrolyte Multilayer Membranes: Erasing the Memory of the Interface. Langmuir 2018, 34, 3874-3883. [CrossRef] [PubMed]

38. Fu, J.; Fares, H.; Schlenoff, J.B. Ion-Pairing Strength in Polyelectrolyte Complexes. Macromolecules 2017, 50, 1066-1074. [CrossRef]

39. Ghostine, R.A.; Markarian, M.Z.; Schlenoff, J.B. Asymmetric Growth in Polyelectrolyte Multilayers. J. Am. Chem. Soc. 2013, 135, 7636-7646. [CrossRef] [PubMed]

40. Bargeman, G. Transport Phenomena during Nanofiltration of Concentrated Solutions. Ph.D. Thesis, University of Twente, Enschede, The Nederland, 2016.

41. Bargeman, G.; Westerink, J.; Miguez, O.G.; Wessling, M. The effect of $\mathrm{NaCl}$ and glucose concentration on retentions for nanofiltration membranes processing concentrated solutions. Sep. Purif. Technol. 2014, 134, 46-57. [CrossRef]

42. Ouyang, L.; Malaisamy, R.; Bruening, M.L. Multilayer polyelectrolyte films as nanofiltration membranes for separating monovalent and divalent cations. J. Membr. Sci. 2008, 310, 76-84. [CrossRef]

43. Liu, C.; Fang, W.; Chou, S.; Shi, L.; Fane, A.; Wang, R. Fabrication of layer-by-layer assembled FO hollow fiber membranes and their performances using low concentration draw solutions. Desalination 2013, 308, 147-153. [CrossRef] 
44. Fritzmann, C.; Lowenberg, J.; Wintgens, T.; Melin, T. State-of-the-art of reverse osmosis desalination. Desalination 2007, 216, 1-76. [CrossRef]

45. Chekli, L.; Phuntsho, S.; Shon, H.; Vigneswaran, S.; Kandasamy, J.; Chanan, A. A review of draw solutes in forward osmosis process and their use in modern applications. Desalination Water Treat. 2012, 43, 167-184. [CrossRef]

46. Melin, T.; Rautenbach, R. Membranverfahren Grundlagen der Modulund Anlagenauslegung; Springer: Berlin/Heidelberg, Germany, 2007.

47. Bowen, W.; Mohammad, A.; Hilal, N. Characterisation of nanofiltration membranes for predictive purposes-Use of salts, uncharged solutes and atomic force microscopy. J. Membr. Sci. 1997, 126, 91-105. [CrossRef]

48. Adusumilli, M.; Bruening, M.L. Variation of Ion-Exchange Capacity, $\zeta$ Potential, and Ion-Transport Selectivities with the Number of Layers in a Multilayer Polyelectrolyte Film. Langmuir 2009, 25, 7478-7485. [CrossRef] [PubMed]

(C) 2020 by the authors. Licensee MDPI, Basel, Switzerland. This article is an open access article distributed under the terms and conditions of the Creative Commons Attribution (CC BY) license (http://creativecommons.org/licenses/by/4.0/). 